\title{
ORIGINAL
}

ARTICLES

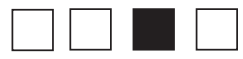

\section{Trends in US Medical School Contributions to the Family Physician Workforce: 2018 Update From the American Academy of Family Physicians}

Julie P. Phillips, MD, MPH; Andrea L. Wendling, MD; Ashley Bentley, MBA; Rae Marsee, MBA; Christopher P. Morley, PhD

BACKGROUND AND OBJECTIVES: The United States needs more family physicians. Projections based on current trends show a deficit of 52,000 primary care physicians by 2025 . Eight national family medicine (FM) organizations have set an ambitious goal of increasing the proportion of US medical school graduates who enter FM residencies to $25 \%$ by 2030 . This paper describes the most recent number and percentage of students from each US medical school entering Accreditation Council for Graduate Medical Education (ACGME)-accredited FM residency programs, long-term trends in the contribution of allopathic and osteopathic medical schools to the FM workforce, and medical school characteristics associated with higher proportions of FM graduates.

METHODS: Data about graduates entering US ACGME-accredited FM residency programs were collected using an annual program census and supplemental sources. Longitudinal census data from allopathic and osteopathic schools were combined to examine trends over time. ANOVA analyses were conducted to compare schools by percent of graduates entering FM, public/private ownership, allopathic/osteopathic, size, and presence of FM department. Medical school length of operation was correlated with percentage of students entering FM.

RESULTS: The overall proportion of US students entering ACGME-accredited FM programs has increased modestly over the past decade. Currently, only $12.6 \%$ of US allopathic and osteopathic seniors enter ACGME-accredited FM programs. Individual medical schools' contributions to the FM workforce are described.

CONCLUSIONS: The proportion of US medical students beginning ACGME-accredited FM residency programs has increased slightly over the last decade. However, significant changes to undergraduate medical education are needed to meet the nation's primary care needs.

(Fam Med. 2019;51(3):241-50.)

doi: 10.22454/FamMed.2019.395617

$\mathbf{T}$ he United States needs more primary care doctors, and in particular, family physicians. Multiple studies demonstrate that where the ratio of primary care physicians to other specialists is higher, quality of care improves and costs go down. ${ }^{1-5}$ Ideally, to most efficiently provide quality health care for a population, at least $40 \%$, and better $50 \%$, of physicians should be practicing in ambulatory-based primary care settings. ${ }^{6}$ The need for adult primary care is particularly significant because the US population is aging and the burden of chronic illness is increasing. ${ }^{7}$ However, many communities are also suffering from shortages of pediatric and maternity care. ${ }^{8-10}$ Family physicians are uniquely positioned to meet these comprehensive population health care needs.

US medical schools, particularly allopathic (MD degree-granting) schools, do a poor job of placing students in family medicine (FM) residency positions. For over a decade, less than $10 \%$ of allopathic students nationally have entered FM residency training. ${ }^{11}$ Although more students enter internal medicine residency programs, only a small percentage of these become primary care physicians..$^{12,13} \mathrm{FM}$ graduates are also more likely to care for underserved and rural populations than primary care internists and pediatricians. ${ }^{9,14}$ In total, the US is expected to experience a shortage of

From the Department of Family Medicine, Michigan State University, East Lansing, MI (Dr Phillips and Dr Wendling); SparrowMSU Family Medicine Residency Program (Dr Phillips); American Academy of Family Physicians, Leawood, KS (Mss Bentley and Marsee); and Department of Public Health \& Preventive Medicine, Department of Family Medicine, and Department of Psychiatry and Behavioral Sciences, State University of New York-Upstate Medical University, Syracuse, NY (Dr Morley). 
approximately 52,000 primary care physicians by $2025 .{ }^{15}$

To address this deficiency, the eight national FM organizations have set an ambitious national goal: that $25 \%$ of graduating US medical students will choose FM by 2030 (25 x 2030). ${ }^{16}$ To accomplish this goal, medical student interest in FM careers must increase substantially. In the 2018 National Residency Matching Program (NRMP) Main Residency Match (NRMP Match), only $9.3 \%$ of matching US allopathic seniors $(1,648)$ chose FM residency positions. ${ }^{17}$ This low percentage does not appear to be due to a limitation in the availability of positions, as only $45.1 \%$ of FM residency positions were filled by graduates of allopathic US medical schools. ${ }^{17}$

A higher proportion, but lower number of osteopathic students choose FM. In 2018, 701 osteopathic students (18.6\% of NRMP-matching osteopathic students) matched into Accreditation Council for Graduate Medical Education (ACGME)accredited FM residencies, ${ }^{18}$ and 505 (33.7\% of AOA-matching students) matched to FM positions in the American Osteopathic Association Intern/Resident Registration Program (AOA Match). ${ }^{19}$ These numbers suggest that current osteopathic student interest in FM is consistent with the national $25 \times 2030$ goal. However, trends suggest that osteopathic student interest in primary care is decreasing. In 2017 , only $10 \%$ of matriculating osteopathic students were interested in FM; a total of only $19 \%$ were interested in primary care. ${ }^{20}$ Indeed, there has been a long-term decline in the proportion of osteopathic physicians practicing primary care. ${ }^{21}$

The last two decades have brought important changes to the composition of applications for residency positions in the United States. There has been substantial growth in the number of applicants applying for first-year positions in the NRMP Match. ${ }^{17}$ The most rapid growth has been in the numbers of osteopathic and international medical graduates. ${ }^{17}$ In the last fifteen years, the number of matching international graduates has doubled, and the number of matching osteopathic graduates has tripled. ${ }^{22}$

The number of osteopathic students participating in the NRMP Match has increased, in part, because many new osteopathic medical schools have been established. ${ }^{23-25}$ The total number of osteopathic medical students matching (through both the NRMP and AOA matches) has increased by $36 \%$ over the last 5 years (from 3,884 to 5,270 since 2014), although the percentage of osteopathic students choosing FM has declined. ${ }^{26,27}$ In addition, with the transition to a single accreditation system for graduate medical education, fewer positions were offered and fewer osteopathic graduates participated in the AOA Match in $2018 .{ }^{17,28}$

The number of allopathic seniors in the NRMP Match has also increased. Between 2002 and 2011, US allopathic medical student enrollment increased by $16 \%$, due to both the establishment of new medical schools and the expansion of existing schools..$^{29}$ In general, medical schools with higher rates of graduates practicing primary care, practicing in rural areas, and caring for underserved populations, underwent the most growth. ${ }^{29}$ Early reports suggest that new medical schools have more diverse student bodies, and students with a lower median parental education level and family income. ${ }^{29}$ These trends could lead to increasing numbers of students choosing FM, as underrepresented minority students and students from lower income families are more likely to choose FM careers. ${ }^{30,31}$ However, the overall proportion of matriculating allopathic students from rural backgrounds has decreased over the last two decades ${ }^{32}$ which could negatively impact the FM workforce.

Each year, the American Academy of Family Physicians (AAFP) publishes a study documenting the number and percent of graduates from each US medical school who enter
FM residency programs, and highlights schools with high percentages and high numbers of graduates who choose FM residencies. ${ }^{33}$ This study continues that annual tradition and also describes trends in the longterm contributions of allopathic and osteopathic medical schools to FM residency programs. In addition, we describe the relative contributions of different types of medical schools based on several institutional characteristics. Understanding changes in the emerging FM workforce over time will inform future predictions. This study will also give FM educators and medical schools a baseline understanding of benchmarks for similar institutions, helping institutions that are engaged in the $25 \times 2030$ mission to establish goals for growth.

\section{Methods \\ Data Collection}

We utilized data collection methods consistent with those reported in previous studies in this series to conduct an annual online census to identify all residents in ACGMEaccredited FM residency programs (AAFP residency census). ${ }^{34}$ The most recent data from the US Liaison Committee on Medical Education (LCME) Annual Medical School Questionnaire, Part II, and the American Association of Colleges of Osteopathic Medicine (AACOM) Fast Facts About Osteopathic Medical Education were also used. ${ }^{35,36} \mathrm{In}$ formation was supplemented with internet searches when needed. For the current report, we collated all AAFP residency census data available at time of analysis (2005-2017 for US allopathic schools; 2009-2017 for osteopathic schools) to examine trends over time during the period of data availability. Residency program matriculates were excluded from analysis if they graduated before the academic year being studied (ie, were not seniors when they matched). Where possible, data were combined for US allopathic and osteopathic medical schools for analysis. International medical schools 
were excluded from the current analysis because of data limitations.

\section{Analysis}

We analyzed data using medical school as the unit of analysis, with each year as a separate entry. Each medical school therefore had up to 13 entries in the final analytic dataset, depending on years of available data. We calculated descriptive statistics (means, counts, standard deviations) for each year and for each medical school. Additional variables represented the following information about each school:

- Percentage of graduates entering FM residencies

- Public vs private ownership

- Allopathic (LCME) vs osteopathic (AOA) accreditation

- Size, with large medical schools being more than one standard deviation (SD) above the aggregate mean for all schools, medium schools within one SD, and small schools more than one SD below the mean

- Department, calculated two ways: (1) as a binary variable, where schools either have a department of FM (or a similar department, such as a department of family and community medicine), or no department; and (2) as a trinary variable that also included a category for a division or center of FM within another academic unit (in the binary categorization this academic unit had been included as no department). Only the binary results are reported, as the difference in results was not meaningful.

- Years in operation

We used analysis of variance (ANOVA) across categories to compare mean percentages of graduates. For variables with more than two categories, we employed standard post hoc tests (eg Tukey) to detect between-category effects. For years in operation, which is a linear variable, we calculated Pearson correlation coefficients.

As a quality control measure, we evaluated whether there were confounding effects for time or for collinear independent variables. A fixed-effects regression model was constructed where:

\section{$\%$ FM Residents=Public $/$ \\ Private+Allopathic/Osteopath ic+Small+Large+Department (binary)+Years}

was calculated, utilizing repeated subjects (medical school) and year as a nested term, and an autoregressive $=1$ (AR1) covariance structure. As the findings were not substantially different, we report results of the basic ANOVA and correlational analyses only.

The AAFP Institutional Review Board granted this study an exemption from review.

\section{Results}

We analyzed data from 179 US allopathic and osteopathic medical schools.

Figure 1 displays the percentages of graduates entering ACGMEaccredited FM residency programs over the last 12 years. Since 2009, the overall proportion of US medical students entering these programs increased from $9.0 \%$ to $12.6 \%$. There was a relatively substantial increase between 2016 and 2017, from 10.6\%

Figure 1: Proportion of US Allopathic and Osteopathic Students Entering ACGMEAccredited Family Medicine Residency Programs, 2005-2017

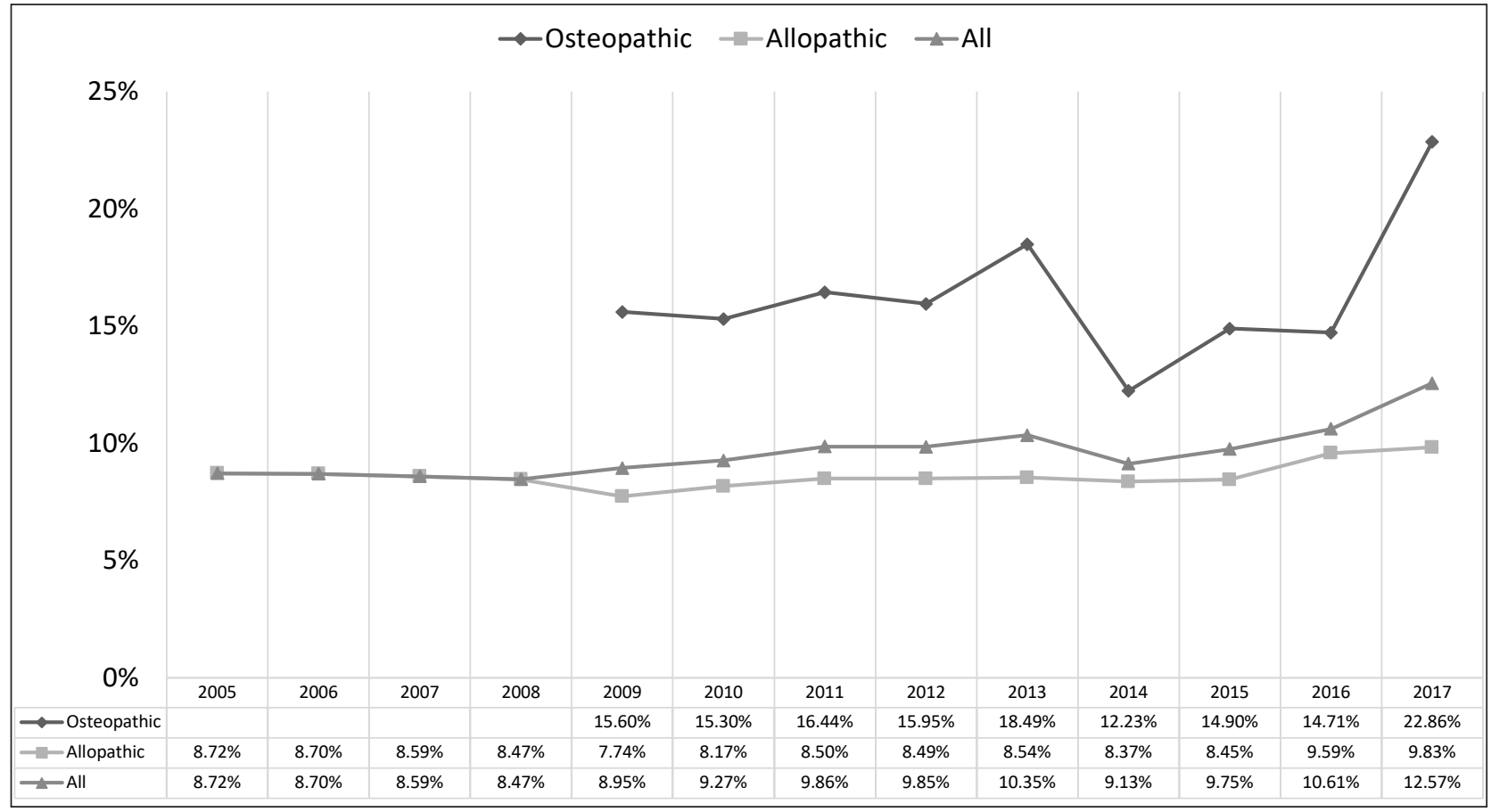


to $12.6 \%$, primarily reflecting an increase in osteopathic graduates entering the ACGME Match. Since 2005 , the proportion of allopathic students matching into FM has increased only slightly from $8.7 \%$ to $9.8 \%$.

At the same time, there has been a substantial increase in the absolute number of US graduates entering ACGME-accredited FM residency programs (Figure 2). Between 2009 and 2017, the number of allopathic and osteopathic US graduates entering FM increased by $78.8 \%$, from 1,814 to 3,243 graduates. Since 2005, the absolute number of allopathic students increased $37.5 \%$ from 1,350 to 1,856 .

Figure 3 shows the overall proportions of allopathic, osteopathic, and international medical school graduates entering US FM residency programs between 2000 and 2017 (because of data limitations, entrants who had graduated before the previous academic year were not removed from this figure). Over this time period, the proportion of US allopathic graduates declined, but has had a slow recovery since 2009; the proportion of osteopathic graduates has more than doubled; and the proportion of US-citizen international graduates has increased. Interestingly, the proportion of nonUS citizen international graduates increased until 2009, and then declined substantially.

Appendix Tables A and B (Appendix tables available online at: https:// journals.stfm.org/media/2150/phillips-appendix-tables-a-i.pdf) list the $20 \%$ of US medical schools with the highest long-term (7-year) contribution to ACGME-accredited FM residency programs, ordered by absolute number of students and proportion of students, respectively. Table 1 lists bright spot institutions that are included on both lists including those with both the highest percentage and number of students entering ACGME-accredited FM programs. Similarly, the short-term (3-year) contributions of high-performing individual medical schools are listed in Appendix Tables C and
$\mathrm{D}$, and short-term bright spots are listed in Table 2. These data do not include information from programs not accredited by the ACGME (osteopathic-only programs), so the total contributions of osteopathic medical schools are underrepresented. Despite this limitation, most of the bright spot institutions are osteopathic $(70.8 \%$ of short-term bright spots and $65.2 \%$ of long-term bright spots).

One-year contributions of highperforming medical schools are listed in Appendix Tables E and F, and 1-year bright spots are displayed in Appendix Table G. Appendix Table $\mathrm{H}$ includes a complete list of all US allopathic and osteopathic medical schools' relative and absolute contributions to ACGME-accredited FM residency programs, organized by state. It is notable that the schools contributing the least to the family medicine workforce are disproportionately private allopathic medical schools and very new medical schools. In contrast, those contributing the most to the family medicine

Figure 2: Number of Allopathic and Osteopathic Students Entering ACGMEAccredited Family Medicine Programs, 2005-2017*

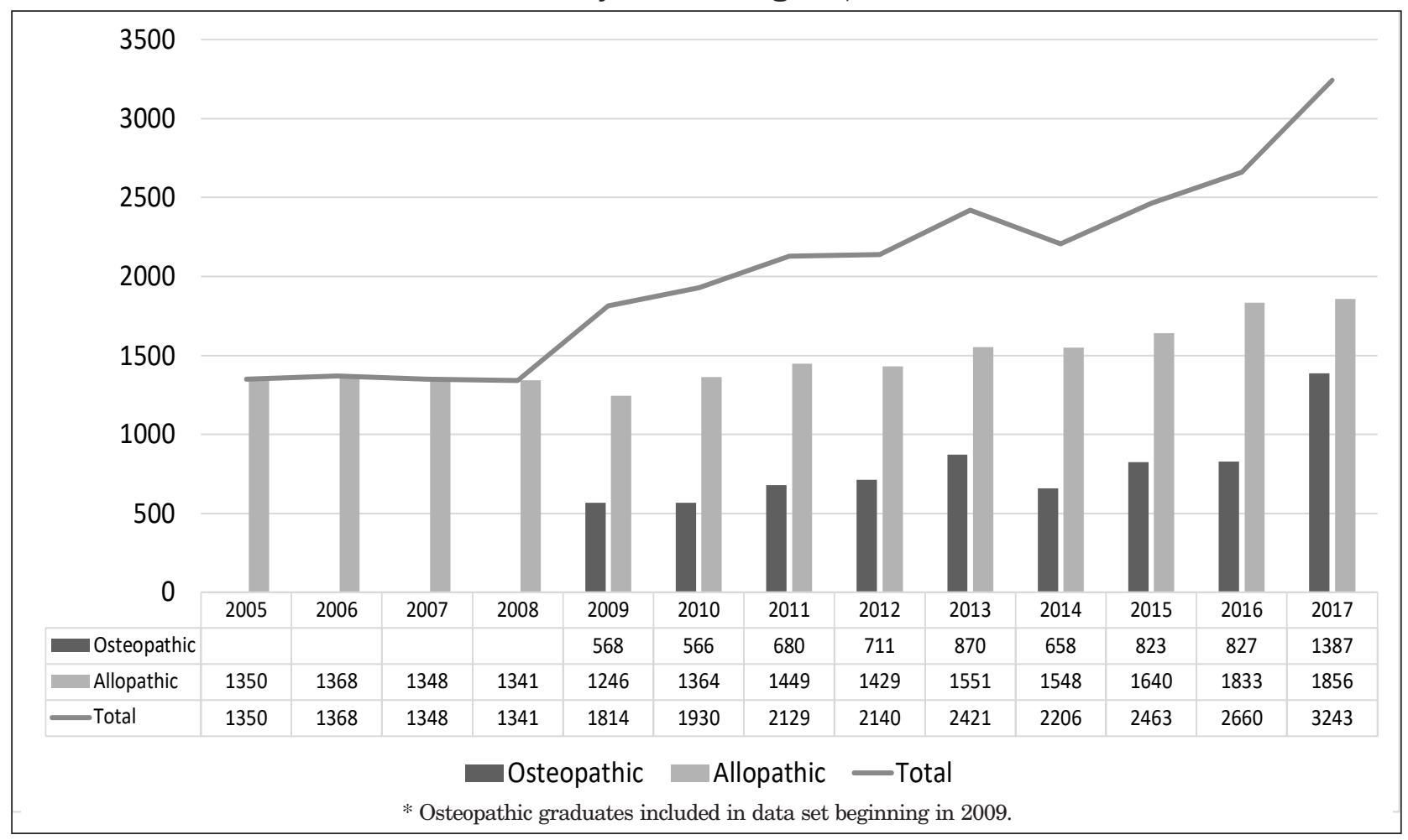


Figure 3: Composition of the Entering Class of ACGME-Accredited Family Medicine Residency Programs by Year, 2000-2017*

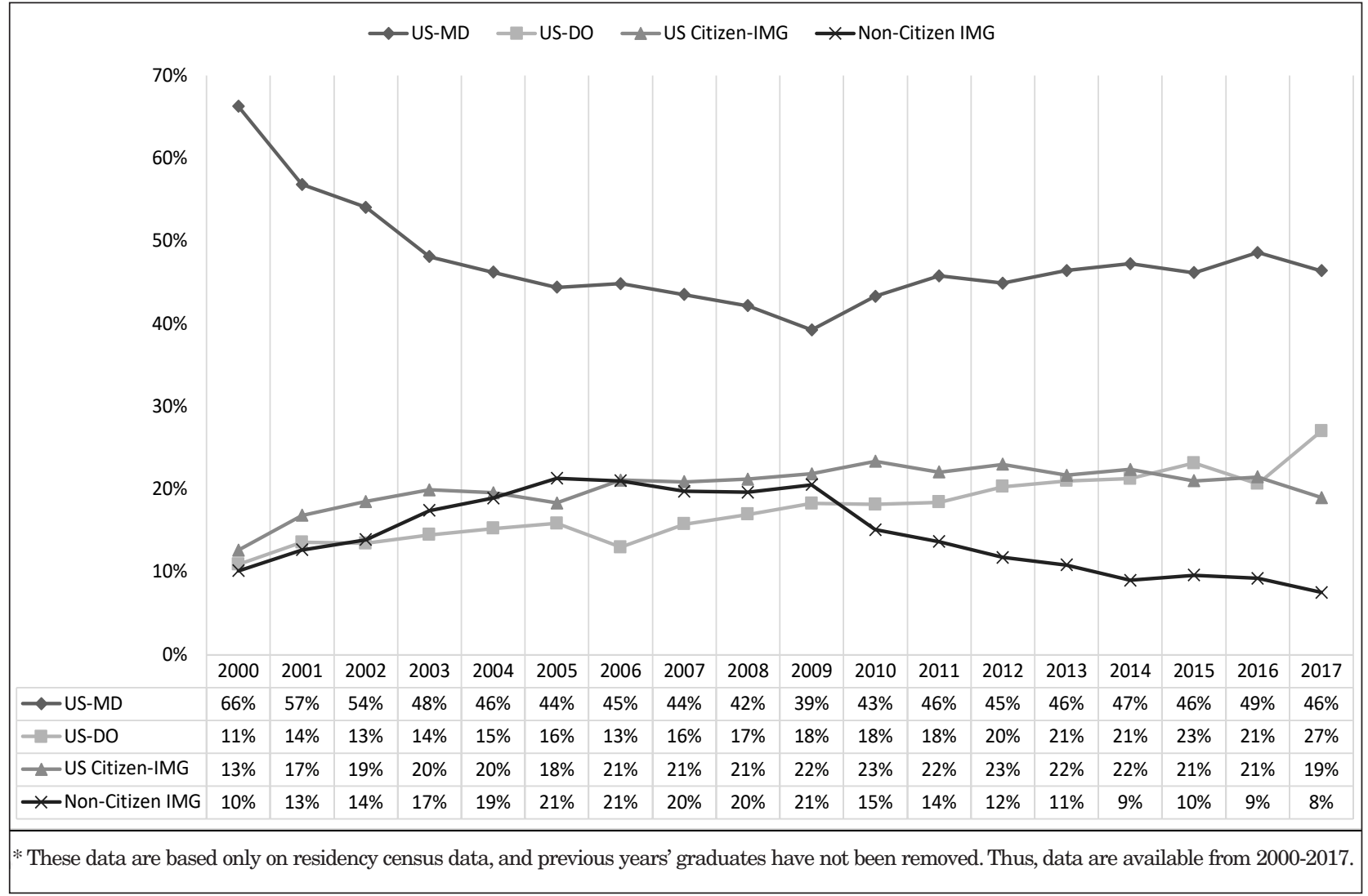

workforce are disproportionately osteopathic medical schools and public allopathic schools, particularly allopathic schools with branch or geographically separated campuses associated with the main institution.

Appendix Table I lists the international medical schools with more than ten graduates entering ACGME-accredited FM programs in 2017, although class size percentages could not be reliably calculated for these institutions. With one exception, all are Caribbean schools.

Table 3 lists medical school characteristics and their relationships with the proportion of students matching to FM. Because these associations differ between allopathic and osteopathic institutions, they are presented separately.

\section{Allopathic Medical Schools}

As has been described previously, public medical schools were more likely to have students enter FM residency training. Interestingly, small medical schools also sent more students to FM programs than medium-sized schools, a difference which has not been reported previously $(10.38 \%$ vs $8.21 \%, P<0.001$; large schools also sent slightly more students to FM residency programs than medium-sized schools, but this difference was small). The presence of a department of family medicine was strongly associated with having more students enter FM programs: only $2.55 \%$ of students from institutions with no department entered FM residency programs $(\mathrm{P}<0.001)$. Allopathic schools that have a disciplinary department structure, but no department of family medicine are noted in Appendix Table $\mathrm{H}$. With two exceptions, all are private, East Coast institutions. There was a negative correlation between institutions' length of operation and the proportion of students choosing FM, indicating that newer medical schools are sending more graduates to FM residency programs than older schools $(r=-0.140, P<0.001)$.

\section{Osteopathic Medical Schools}

In contrast with allopathic schools, private osteopathic medical schools sent more students to FM programs than public schools $(17.04 \%$ vs $14.34 \%, P=0.01$ ), and larger schools graduated a higher proportion of FM residents than smaller ones $(P=0.021)$. The presence of a department was not associated with the proportion of students choosing FM. There was also a correlation between the age of the school and the proportion of students choosing FM, but this correlation was reversed in direction: students from newer schools were less likely to choose FM $(\mathrm{r}=0.196 ; P=0.001)$. 
Table 1: Long-Term Contribution to the Family Medicine Workforce: Bright Spots

\begin{tabular}{|c|c|c|c|}
\hline State & Medical School & $\begin{array}{c}\text { Number of } \\
\text { Graduates } \\
\text { Entering FM } \\
\text { Residencies } \\
2011-2017\end{array}$ & $\begin{array}{c}\text { Percent of } \\
\text { Graduates } \\
\text { Entering FM } \\
\text { Residencies } \\
\text { 2011-2017 }\end{array}$ \\
\hline Arizona & A.T. Still University-School of Osteopathic Medicine in Arizona & 160 & 23.5 \\
\hline Arkansas & University of Arkansas for Medical Sciences College of Medicine & 176 & 15.9 \\
\hline \multirow{3}{*}{ California } & Loma Linda University School of Medicine & 169 & 14.8 \\
\hline & Touro University College of Osteopathic Medicine-California & 220 & 24.8 \\
\hline & $\begin{array}{l}\text { Western University of Health Sciences/College of Osteopathic } \\
\text { Medicine of the Pacific }\end{array}$ & 395 & 26.6 \\
\hline Illinois & Chicago College of Osteopathic Medicine of Midwestern University & 301 & 23.0 \\
\hline Iowa & Des Moines University College of Osteopathic Medicine & 412 & 27.4 \\
\hline Kansas & University of Kansas School of Medicine & 230 & 18.1 \\
\hline Maine & University of New England College of Osteopathic Medicine & 161 & 18.0 \\
\hline Michigan & Michigan State University College of Osteopathic Medicine & 245 & 16.5 \\
\hline Minnesota & University of Minnesota Medical School & 275 & 17.3 \\
\hline \multirow{2}{*}{ Missouri } & A.T. Still University-Kirksville College of Osteopathic Medicine & 225 & 19.3 \\
\hline & $\begin{array}{l}\text { Kansas City University of Medicine and Biosciences College of } \\
\text { Osteopathic Medicine }\end{array}$ & 271 & 16.2 \\
\hline Oregon & Oregon Health \& Science University School of Medicine & 151 & 17.5 \\
\hline \multirow{2}{*}{ Pennsylvania } & Lake Erie College of Osteopathic Medicine & 305 & 17.4 \\
\hline & Philadelphia College of Osteopathic Medicine & 336 & 18.3 \\
\hline Tennessee & $\begin{array}{l}\text { Lincoln Memorial University-DeBusk College of Osteopathic } \\
\text { Medicine }\end{array}$ & 185 & 17.4 \\
\hline \multirow[b]{2}{*}{ Texas } & Texas Tech University Health Sciences Center School of Medicine & 147 & 14.8 \\
\hline & $\begin{array}{l}\text { University of North Texas Health Science Center at Fort Worth } \\
\text { Texas College of Osteopathic Medicine }\end{array}$ & 298 & 21.7 \\
\hline Virginia & Edward Via College of Osteopathic Medicine-Virginia Campus & 234 & 18.6 \\
\hline Washington & University of Washington School of Medicine & 260 & 17.2 \\
\hline West Virginia & West Virginia School of Osteopathic Medicine & 211 & 16.4 \\
\hline Wisconsin & University of Wisconsin School of Medicine and Public Health & 177 & 15.4 \\
\hline
\end{tabular}

US medical schools that fell within both the top 20th percentile for total graduates and the top 20th percentile for percent of graduating class entering into ACGME-accredited family medicine residency programs, over the past 7 years, listed in alphabetical order by state. Shaded schools are allopathic (MD granting); nonshaded schools are osteopathic (DO granting).

\section{Discussion}

Over the last decade, there has been a substantial increase in the number of US medical school graduates entering ACGME-accredited FM residency programs. However, this primarily reflects an increase in number of overall graduates and a shift toward ACGME accreditation, rather than a substantial change in student choice of family medicine. We are not on track to meet our 25 x 2030 goal. Osteopathic students represent a growing proportion of students in ACGME-accredited residencies, and osteopathic students are substantially more likely to match to FM residency programs than US allopathic students. However, this trend should be interpreted with caution because it represents a migration of these students from AOA-accredited programs to ACGME-accredited programs, rather than an actual increase in osteopathic student interest. ${ }^{17,28}$

Allopathic medical schools have undergone substantial growth in the last two decades, and our findings indicate that newer institutions, as a group, graduate more family physicians. This may reflect different recruitment and admissions practices, as newer schools appear to be accepting more racially and ethnically diverse students and students from lower income families. ${ }^{37}$ Newer allopathic schools also have more mission focus on innovation, which may be reflected in more primary-carefocused curricula. ${ }^{38}$ More research is needed to better understand best 
Table 2: Three-Year Contribution to the Family Medicine Workforce: Bright Spots

\begin{tabular}{|c|c|c|c|}
\hline State & School & $\begin{array}{c}\text { Number of } \\
\text { graduates } \\
\text { entering FM } \\
\text { residencies } \\
2015-2017\end{array}$ & $\begin{array}{c}\text { Percent of } \\
\text { graduates } \\
\text { entering FM } \\
\text { residencies } \\
2015-2017\end{array}$ \\
\hline Arizona & A.T. Still University-School of Osteopathic Medicine in Arizona & 81 & 26.0 \\
\hline Arkansas & University of Arkansas for Medical Sciences College of Medicine & 93 & 18.6 \\
\hline \multirow{3}{*}{ California } & Loma Linda University School of Medicine & 79 & 15.9 \\
\hline & Touro University College of Osteopathic Medicine-California & 106 & 27.4 \\
\hline & $\begin{array}{l}\text { Western University of Health Sciences/College of Osteopathic } \\
\text { Medicine of the Pacific }\end{array}$ & 181 & 28.1 \\
\hline Colorado & Rocky Vista University College of Osteopathic Medicine & 78 & 17.6 \\
\hline Illinois & Chicago College of Osteopathic Medicine of Midwestern University & 146 & 24.6 \\
\hline Iowa & Des Moines University College of Osteopathic Medicine & 175 & 27.5 \\
\hline Kansas & University of Kansas School of Medicine & 108 & 18.4 \\
\hline Maine & University of New England College of Osteopathic Medicine & 69 & 17.3 \\
\hline \multirow{2}{*}{ Michigan } & Michigan State University College of Human Medicine & 104 & 17.5 \\
\hline & Michigan State University College of Osteopathic Medicine & 132 & 22.3 \\
\hline Minnesota & University of Minnesota Medical School & 134 & 19.3 \\
\hline Missouri & A.T. Still University-Kirksville College of Osteopathic Medicine & 104 & 21.0 \\
\hline Ohio & Ohio University Heritage College of Osteopathic Medicine & 70 & 17.9 \\
\hline \multirow{2}{*}{ Pennsylvania } & Lake Erie College of Osteopathic Medicine & 137 & 17.9 \\
\hline & Philadelphia College of Osteopathic Medicine & 144 & 18.6 \\
\hline South Carolina & Edward Via College of Osteopathic Medicine-Carolinas Campus & 85 & 18.3 \\
\hline Tennessee & $\begin{array}{l}\text { Lincoln Memorial University-DeBusk College of Osteopathic } \\
\text { Medicine }\end{array}$ & 104 & 19.4 \\
\hline \multirow[b]{2}{*}{ Texas } & Texas Tech University Health Sciences Center School of Medicine & 72 & 16.9 \\
\hline & $\begin{array}{l}\text { University of North Texas Health Science Center Texas College of } \\
\text { Osteopathic Medicine }\end{array}$ & 152 & 22.7 \\
\hline Virginia & Edward Via College of Osteopathic Medicine-Virginia Campus & 124 & 22.4 \\
\hline Washington & University of Washington School of Medicine & 110 & 16.6 \\
\hline West Virginia & West Virginia School of Osteopathic Medicine & 87 & 15.8 \\
\hline
\end{tabular}

US medical schools that fell within both the top 20th percentile for total graduates and the top 20th percentile for percent of graduating class entering ACGME-accredited family medicine residency programs, over the past 3 years, listed in alphabetical order by state. Shaded schools are allopathic (MD granting); nonshaded schools are osteopathic (DO granting).

practices to promote student choice of FM at new institutions.

On the other hand, newer osteopathic medical schools sent fewer graduates to FM residency programs than established osteopathic schools. Initially, we considered that this might reflect the movement toward privatization of osteopathic medical schools. All of the osteopathic medical schools established in the last 40 years have been private, ${ }^{39}$ and multiple studies have demonstrated that private allopathic medical schools graduate fewer family physicians. ${ }^{40}$ However, our results also indicate that private osteopathic schools actually send more students to FM residency programs than public schools do. It is possible that older, more established private osteopathic institutions maintain a stronger educational and mission orientation toward FM than newer institutions, as the philosophy of osteopathic medicine focuses on whole-person, health-oriented, preventive, patient-centered care. ${ }^{23}$ At the same time, the public osteopathic medical schools are the most established of all osteopathic medical schools, and this comparative prestige may contribute to students exploring more competitive specialty positions.

However, these hypotheses are speculative, and more research is needed to understand the characteristics of osteopathic medical schools that contribute to a higher 
Table 3: Proportion of Students Matriculating to ACGME-Accredited Family Medicine Residency Programs, Compared Across Institutional Characteristics

\begin{tabular}{|c|c|c|c|c|c|c|c|}
\hline \multirow{2}{*}{\multicolumn{2}{|c|}{ Institutional Characteristics }} & \multirow{2}{*}{\multicolumn{2}{|c|}{$\begin{array}{c}\text { Allopathic }(n=140) \\
8.64 \%\end{array}$}} & \multirow{2}{*}{\multicolumn{2}{|c|}{$\begin{array}{c}\text { Osteopathic }(\mathrm{n}=37) \\
16.41 \%\end{array}$}} & \multirow{2}{*}{\multicolumn{2}{|c|}{$\begin{array}{c}\text { Combined }(\mathrm{n}=177) \\
9.70 \%\end{array}$}} \\
\hline & & & & & & & \\
\hline & & \multirow{2}{*}{$\begin{array}{l}\text { Mean } \\
6.00 \%\end{array}$} & \multirow{3}{*}{$\begin{array}{c}\boldsymbol{P} \\
<.001\end{array}$} & \multirow{3}{*}{\begin{tabular}{|c|} 
Mean \\
$17.04 \%$ \\
$14.34 \%$ \\
\end{tabular}} & \multirow{3}{*}{$\begin{array}{c}\boldsymbol{P} \\
0.01\end{array}$} & \multirow{2}{*}{$\begin{array}{l}\text { Mean } \\
8.59 \% \\
\end{array}$} & \multirow{3}{*}{$\begin{array}{c}\boldsymbol{P} \\
<.001\end{array}$} \\
\hline \multirow{2}{*}{$\begin{array}{l}\text { Public/ } \\
\text { private }\end{array}$} & Private $(\mathrm{n}=91)^{*}$ & & & & & & \\
\hline & Public $(\mathrm{n}=100)$ & $10.36 \%$ & & & & $10.60 \%$ & \\
\hline \multirow{3}{*}{ Size } & Small $(n=40)$ & $10.38 \%$ & \multirow{3}{*}{$<.001$} & $13.44 \%$ & \multirow{3}{*}{0.021} & $10.63 \%$ & \multirow{3}{*}{$<.001$} \\
\hline & Average $(\mathrm{n}=117)$ & $8.21 \%$ & & $16.12 \%$ & & $9.13 \%$ & \\
\hline & Large $(\mathrm{n}=34)$ & $8.78 \%$ & & $17.84 \%$ & & $11.47 \%$ & \\
\hline Department & No $(n=17)$ & $2.55 \%$ & \multirow{2}{*}{$<.001$} & 16.56 & \multirow{2}{*}{ NS } & $7.40 \%$ & \multirow{2}{*}{$<.001$} \\
\hline of FM & Yes $(n=126)$ & $9.23 \%$ & & 16.35 & & $10.01 \%$ & \\
\hline \multirow{2}{*}{$\begin{array}{l}\text { Years in } \\
\text { operation }\end{array}$} & \multirow{2}{*}{$\begin{array}{l}\text { Correlation of years } \\
\text { in operation with } \\
\text { percentage choosing } \\
\text { FM }\end{array}$} & Pearson $r$ & $P$ & Pearson $r$ & $P$ & Pearson $r$ & $P$ \\
\hline & & -0.140 & $<.001$ & 0.196 & 0.001 & -0.243 & $<.001$ \\
\hline
\end{tabular}

*Numbers in each category calculated as of 2017.

Means compared using ANOVA. Reported means are aggregated across all years in which data are available, 2005-2017.

proportion of FM graduates. Compared to allopathic students, osteopathic student interest seems robust, but data suggest this interest has sharply declined with the transition toward merged osteopathic/allopathic training and practice. ${ }^{20,21,23}$ In the recent past, the majority of osteopathic physicians practiced primary care. ${ }^{23}$ Declining osteopathic student interest in FM is of significant concern and deserves the full attention of our leadership.

Finally, the presence of a department of FM was strongly associated with the proportion of students entering FM residency programs from allopathic institutions. Because our data includes a limited number of institutional variables, the presence of a department may be a proxy for other variables, such as the presence of an FM clerkship, the presence of FM leaders, or students' contact with FM faculty. Nonetheless, an FM department appears to be a marker for meaningful institutional power and influence, which has been correlated with student career choice in previous research. ${ }^{41-43}$ Newly established allopathic medical schools should be attentive to this relationship, and consider establishing FM departments in order to promote student interest in FM. Interestingly, this variable had no relationship with student choice among osteopathic schools. This may be because osteopathic institutions, as a whole, have a strong FM orientation, whereas within allopathic institutions FM education is seen as one of many competing interests.

\section{Limitations}

This analysis only measures residents who begin AGCME-accredited FM residency programs. This means that a substantial proportion of osteopathic graduates are not captured. Because other data sources demonstrate that osteopathic student interest in FM is actually decreasing, we believe the apparent increase in our analysis is artifactual. Second, because the analyses were focused on predictors of the proportion of students choosing FM and reliable class size data were not available for international medical school schools, international medical graduates are listed in the descriptive tables but not included in the analyses. Finally, the institutional analyses included only a limited number of variables. A number of other institutional characteristics such as the presence of rural training programs, ${ }^{44}$ the presence of regional campuses, ${ }^{45}$ the robustness of FM curricula, ${ }^{40,41,46,47}$ and the institutional culture, ${ }^{48-50}$ have been shown to contribute to the proportion of graduates choosing FM. Future analyses should consider these key variables, among others.

\section{Conclusions}

Although the proportion of US medical students beginning FM residency programs has increased modestly over the last decade, only $12.6 \%$ of US allopathic and osteopathic medical school graduates are entering ACGME-accredited family medicine residency programs. Significant changes are needed for the specialty to reach a national goal of $25 \%$ of US graduates choosing family medicine by 2030 . A change in course of this magnitude will require substantial changes to undergraduate medical education in the United States.

ACKNOWLEDGMENTS: The authors thank Iris Kovar-Gough, MA, MLIS, for her assistance with literature searches; Jennifer EdwardsJohnson, DO, and Amy Odom, DO, for their critical review; Alexandra Travis for survey design and data collection; and Joshua Freeman, MD, for his early contributions to framing of this work. 
CORRESPONDING AUTHOR: Address correspondence to Dr Christopher Morley, 2262 Weiskotten Hall, 766 Irving Ave, Syracuse NY 13210. 315-464-1520. Fax: 315-464-1701. morleycp@upstate.edu.

\section{References}

1. Stanford Medicine Clinical Excellence Research Center. America's Most Valuable Care. https://petersonhealthcare.org/sites/default/ files/images/media_library/Peterson $\% 20 \mathrm{Cen}$ ter\%20on\%20Healthcare_Stanford\%20Overview_1.pdf. Accessed July 14, 2017.

2. Saultz JW, Lochner J. Interpersonal continuity of care and care outcomes: a critical review. Ann Fam Med. 2005;3(2):159-166. https://doi. org/10.1370/afm.285

3. Bazemore A, Petterson S, Peterson LE, Phillips RL Jr. More comprehensive care among family physicians is associated with lower Costs and fewer hospitalizations. Ann Fam Med. 2015;13(3):206-213. https://doi.org/10.1370/ afm. 1787

4. Starfield B, Shi L, Macinko J. Contribution of primary care to health systems and health. Milbank Q. 2005;83(3):457-502. https://doi. org/10.1111/j.1468-0009.2005.00409.x

5. Macinko J, Starfield B, Shi L. The contribution of primary care systems to health outcomes within Organization for Economic Cooperation and Development (OECD) countries, 19701998. Health Serv Res. 2003;38(3):831-865. https://doi.org/10.1111/1475-6773.00149

6. Sandy LG, Bodenheimer T, Pawlson LG, Starfield B. The political economy of U.S. primary care. Health Aff (Millwood). 2009;28(4):1136-1145. https://doi.org/10.1377/ hlthaff.28.4.1136

7. Institute of Medicine Committee on the Future Health Care Workforce for Older Americans. Retooling for an Aging America: Building the Health Care Workforce. IOM Report in Brief; April, 2008. http://nationalacademies. org/hmd/ /media/Files/Report\%20Files/2008/ Retooling-for-an-Aging-America-Building-theHealth-Care-Workforce/ReportBriefRetoolingforanAgingAmericaBuildingtheHealthCareWorkforce.pdf. Accessed October 23, 2018.

8. Basco WT, Rimsza MECommittee on Pediatric Workforce; American Academy of Pediatrics. Pediatrician workforce policy statement. Pediatrics. 2013;132(2):390-397.

9. Phillips RL, Dodoo MS, McCann JL, et al. Report to the Task Force on the Care of Children by Family Physicians. Washington, DC: The Robert Graham Center; 2005. https://www. graham-center.org/content/dam/rgc/documents/ publications-reports/monographs-books/rgcmocare-children.pdf. Accessed October 24, 2018.

10. Rayburn WF. The Obstetrician- Gynecologist Workforce in the United States. Washington, DC: The American College of Obstetricians and Gynecologists; 2017. https://m.acog.org/ /media/ BB3A7629943642ADA47058D0BDCD1521. pdf. Accessed October 24, 2018.

11. Freeman J, McGrew M. Producing family physicians: our medical schools must do a better job. Ann Fam Med. 2012;10(2):178-179.
12. West CP, Dupras DM. General medicine vs subspecialty career plans among internal medicine residents. JAMA. 2012;308(21):2241-2247.

13. The Robert Graham Center. The State of Primary Care in the United States: A Chartbook of Facts and Statistics. https://www.grahamcenter.org/content/dam/rgc/documents/publications-reports/reports/PrimaryCareChartbook. pdf. Accessed October 12, 2018.

14. Xierali IM. Distributional differences between family physicians and general internists. $J$ Health Care Poor Underserved. 2018;29(2):711722.

15. Petterson SM, Liaw WR, Phillips RL Jr, Rabin DL, Meyers DS, Bazemore AW. Projecting US primary care physician workforce needs: 2010 2025. Ann Fam Med. 2012;10(6):503-509.

16. Family Medicine For America's Health. September 2018 Update. https://fmahealth.org/ september-2018-monthly-update/. Accessed October 7, 2018.

17. National Resident Matching Program. Results and Data: 2018 Main Residency Match. https:// mk0nrmpcikgb8jxyd19h.kinstacdn.com/wpcontent/uploads/2018/04/Main-Match-Resultand-Data-2018.pdf. Accessed October 7, 2018

18. National Resident Matching Program. Charting Outcomes in the Match: Senior Students of U.S. Osteopathic Medical Schools. http:// www.nrmp.org/wp-content/uploads/2018/06/ Charting-Outcomes-in-the-Match-2018-Osteo. pdf. Accessed October 7, 2018.

19. National Matching Services, Inc. Summary of Positions Offered and Filled by Program Type. https://natmatch.com/aoairp/ stats/2018prgstats.html. Accessed October 7, 2018 .

20. American Association of Colleges of Osteopathic Medicine. 2017-18 Entering Student Survey Summary Report. https://www.aacom. org/docs/default-source/data-and-trends/aacom2017-18-entering-student-survey-summary-report.pdf?sfvrsn=66ac2797_4. Accessed October 7, 2018.

21. Barnes K, Petterson S, Bazemore A. Osteopathic schools are producing more graduates, but fewer are practicing in primary care. Am Fam Physician. 2015;91(11):756.

22. National Resident Matching Program. FirstYear Graduate Medical Education in the United States: 2002-2017. http://www.nrmp. org/wp-content/uploads/2018/02/First-YearGME-in-the-US-2017.pdf. Accessed October $12,2018$.

23. Shannon SC, Teitelbaum HS. The status and future of osteopathic medical education in the United States. Acad Med. 2009;84(6):707-711.

24. Gevitz N. The transformation of osteopathic medical education. Acad Med. 2009;84(6):701706.

25. American Association of Colleges of Osteopathic Medicine. Trends in Osteopathic Medical School Applicants, Enrollment, and Graduates. https://www.aacom.org/docs/defaultsource/data-and-trends/2018-trends-com-aeg. pdf?sfvrsn=d2ba4c97_66. Accessed October 12, 2018
26. American Academy of Family Physicians. 2018 Match Results for Family Medicine. https:// www.aafp.org/medical-school-residency/program-directors/nrmp.html. Accessed October $23,2018$.

27. Kozakowski SM, Travis A, Marcinek JP, Bentley A, Fetter GT Jr. Results of the 2017 National Resident Matching Program and the American Osteopathic Association Intern/ Resident Registration Program. Fam Med. 2017;49(9):679-685.

28. National Matching Services, Inc. Match Statistics, 2019. https://natmatch.com/aoairp/aboutstats.html. Accessed September 7, 2018.

29. Shipman SA, Jones KC, Erikson CE, Sandberg SF. Exploring the workforce implications of a decade of medical school expansion: variations in medical school growth and changes in student characteristics and career plans. Acad Med. 2013;88(12):1904-1912

30. Xierali IM, Nivet MA. The racial and ethnic composition and Distribution of Primary Care Physicians. J Health Care Poor Underserved. 2018;29(1):556-570.

31. Cooter R, Erdmann JB, Gonnella JS, Callahan CA, Hojat M, Xu G. Economic diversity in medical education: the relationship between students' family income and academic performance, career choice, and student debt. Eval Health Prof. 2004;27(3):252-264.

32. Shipman S, Wendling A, Phillips J, KovarGough I, K J. Rural medical students, rural physicians: Can an evaporating pool meet a perennial need? Presnentation at the 2018 AAMC Heathcare Workforce Research Conference in Tysons, Virginia.

33. Kozakowski SM, Travis A, Marcinek JP, Bentley A, Fetter GT Jr. Entry of medical school graduates into family medicine residencies: 2016-2017. Fam Med. 2017;49(9):686-692.

34. Kozakowski SM, Travis A, Bentley A, Fetter G Jr. Entry of US medical school graduates into family medicine residencies: 2015-2016. Fam Med. 2016;48(9):688-695.

35. Barzansky B, Etzel SI. Medical Schools in the United States, 2016-2017. JAMA. 2017;318(23):2360-2367.

36. American Association of Colleges of Osteopathic Medicine. Fast Facts About Osteopathic Medical Education. https://www.aacom.org/ news-and-events/fastfacts. Accessed October $22,2018$.

37. Shipman SA, Jones KC, Erikson CE, Sandberg SF. Exploring the workforce implications of a decade of medical school expansion: variations in medical school growth and changes in student characteristics and career plans. Acad Med. 2013;88(12):1904-1912.

38. Dupper M, Millard H, Lyons P. Shifting concepts, changing contexts: the new schools' drive for change. Adv Health Sci Educ Theory Pract. 2016;21(1):131-139.

39. American Association of Colleges of Osteopathic Medicine. U.S. Osteopathic Medical Schools by Year of Inaugural Class. 2017. https://www.aacom.org/docs/default-source/ data-and-trends/u-s-osteopathic-medicalschools-by-year-of-inaugural-class.pdf?sfvrsn=4. Accessed October 12, 2018. 
40. Bennett KL, Phillips JP. Finding, recruiting, and sustaining the future primary care physician workforce: a new theoretical model of specialty choice process. Acad Med. 2010;85(10) (suppl):S81-S88.

41. Senf JH, Campos-Outcalt D, Watkins AJ, Bastacky S, Killian C. A systematic analysis of how medical school characteristics relate to graduates' choices of primary care specialties. Acad Med. 1997;72(6):524-533.

42. Campos-Outcalt D, Senf J, Watkins AJ, Bastacky S. The effects of medical school curricula, faculty role models, and biomedical research support on choice of generalist physician careers: a review and quality assessment of the literature. Acad Med. 1995;70(7):611-619.

43. Whitcomb ME, Cullen TJ, Hart LG, Lishner DM, Rosenblatt RA. Comparing the characteristics of schools that produce high percentages and low percentages of primary care physicians. Acad Med. 1992;67(9):587-591.
44. Wendling AL, Phillips J, Short W, Fahey C, Mavis B. Thirty Years Training Rural Physicians: Outcomes From the Michigan State University College of Human Medicine Rural Physician Program. Acad Med. 2016;91(1):113-119.

45. Phillips JP, Wendling AL, Fahey CA, Mavis $\mathrm{BE}$. The effect of a community-based medical school on the state and local physician workforce. Acad Med. 2018;93(2):306-313.

46. Phillips J, Charnley I. Third- and fourth-year medical students' changing views of family medicine. Fam Med. 2016;48(1):54-60

47. Phillilps RL, Dodoo MS, Petterson S, et al Specialty and Geographic Distribution of the Physician Workforce: What Influences Medical Student \& Resident Choices? Washington, DC The Robert Graham Center; 2009. https://www. graham-center.org/dam/rgc/documents/publications-reports/monographs-books/Specialtygeography-compressed.pdf. Accessed October 24,2018
48. Wendling AL, Wudyka AE, Phillips JP, et al. RU4PC? Texting to quantify feedback about primary care and its relationship with student career interest. Fam Med. 2016;48(1):21-29.

49. Erikson CE, Danish S, Jones KC, Sandberg SF, Carle AC. The role of medical school culture in primary care career choice. Acad Med. 2013;88(12):1919-1926.

50. Morley CP, Mader EM, Smilnak T, et al. The social mission in medical school mission statements: associations with graduate outcomes. Fam Med. 2015;47(6):427-434 